\title{
Trabalho feminino na indústria do vestuário*
}

Raquel da Silva Gazzona**

RESUMO: Este artigo analisa as mudanças que vêm ocorrendo em uma empresa de grande porte do ramo do vestuário do Rio Grande do Sul e suas relações com as formas de ocupação, controle e qualificação da mão-de-obra feminina. Predominam, na empresa estudada, a baixa escolaridade, os baixos níveis salariais entre as trabalhadoras e a organização do trabaIho baseada no parcelamento de tarefas. No entanto, a partir da introdução de tecnologia microeletrônica e de novas formas de gestão da mão-de-obra abrem-se, em pontos estratégicos da produção, oportunidades de treinamento e reinserção profissional para algumas mulheres.

Palavras-chave: Trabalho, mulher, indústria do vestuário, inovação tecnológica e qualificação.

Estudos recentes vêm mostrando que a reestruturação produtiva, evidenciada na rápida difusão de inovações tecnológicas e nas novas formas de organização do trabalho e gestão da mão-de-obra, a partir da indústria automobilística, atinge de forma diferenciada os diversos setores da economia. Da mesma forma, diferenciadas são as relações entre estas transformações e as novas (ou velhas) demandas por qualificação. As formas de trabalho na indústria do vestuário, considerada um

\footnotetext{
* Este texto integra o relatório final do projeto "Novas tecnologias, formação, inserção e reinserção profissional" do Programa de Pesquisa em Ciência e Tecnologia, Qualificação e Produção, do Cedes, e financiado pela Finep-Proeduc e PCDT-CNPq.

** Bacharel em Ciências Sociais pela Universidade do Rio Grande do Sul.
} 
segmento tradicional da indústria de transformação, onde é majoritária a presença feminina, constituem o objeto deste estudo.

Foram coletados dados secundários da Rais/MTb e do Caged/ MTb, bem como realizadas entrevistas no Sindicato das Indústrias, no Sindicato dos Trabalhadores do Vestuário do Rio Grande do Sul e no Senai-Costura. Um estudo de caso, durante o ano de 1996, foi desenvolvido em uma das maiores empresas do ramo do vestuário do Estado, localizada em Porto Alegre. Nesta empresa foram realizadas entrevistas com o diretor industrial, o gerente técnico, com encarregadas do setor de montagem, com a supervisora e trabalhadoras do setor de modelagem.

Pretende-se discutir, neste estudo, em que medida a reestruturação produtiva atinge uma grande empresa exportadora em um setor tradicional da economia, como a indústria do vestuário. Quais as estratégias adotadas pela referida empresa e até que ponto estas estratégias, em um contexto de acirramento da concorrência, afetam a qualificação da mão-de-obra feminina em termos de escolaridade, programas de treinamento/reinserção, formas de controle e ocupação? Privilegia-se a mãode-obra feminina, tendo em vista serem as mulheres majoritárias no ramo do vestuário, o que permite ainda observar se, a partir de tais mudanças que vêm ocorrendo na estrutura produtiva, surgem novas oportunidades para as trabalhadoras, com acesso a postos com maior conteúdo tecnológico, possibilidades de carreira e promoção.

Na primeira parte deste artigo são levantadas algumas questões sobre como interpretar a divisão sexual do trabalho à luz dos estudos sobre relações de gênero; na segunda parte são apresentadas as principais características da indústria do vestuário localizada no Rio Grande do Sul. Seguem-se, então, o detalhamento do estudo de caso e as considerações finais da pesquisa.

\section{Sobre a divisão sexual do trabalho}

A ampliação e a diversificação da participação feminina no mercado de trabalho no Brasil, nos anos 70 , quando as mulheres passaram a ser incorporadas em setores das indústrias elétrica e eletrônica, bem como a persistência e o aumento desta participação, nos anos 80 e 90 , principalmente nas atividades ligadas ao setor de serviços como comércio, administração pública e setor social (Bruschini 1993), trouxeram à tona 
uma infinidade de questões. Entre estas cabe citar a importância das conquistas do movimento feminista para, nas palavras de Souza-Lobo (1991), "sacudir as estruturas da produção sociológica" no que concerne à incorporação da variável sexo nas pesquisas sobre relações de trabalho.

No entanto, se, por um lado, as mulheres vêm conquistando novos espaços no mercado de trabalho, por outro, concentram-se em setores e ocupações definidos como tradicionalmente femininos. É o caso das indústrias têxtil e do vestuário, ramos que perderam dinamismo interno e o comando sobre o crescimento da indústria, a partir de 1950, e que, por muitas décadas, constituíram umas das poucas possibilidades de emprego fora do lar para as mulheres menos instruídas (Pena 1981).

Ao longo do tempo, muitas foram as respostas dadas à pergunta sobre qual a lógica que preside a divisão sexual do trabalho por postos e setores de atividade econômica, atingindo salários, promoções, qualificação, escala de funções e formas de controle da mão-de-obra. Estaria a lógica da divisão sexual do trabalho baseada na oposição trabalho leve (feminino)/trabalho pesado (masculino), de modo que a difusão das inovações microeletrônicas equalizaria homens e mulheres no mercado de trabalho? O trabalho feminino na indústria seria apenas uma continuação de atividades antes exercidas na esfera doméstica? Os baixos salários femininos poderiam ser explicados com base no argumento de que o trabalho da mulher é complementar ao trabalho do homem/marido?

A diversidade e a complexidade das formas de uso da mão-deobra feminina sugerem que não existem fatores naturais, inerentes ou lógicos que instituam a divisão sexual do trabalho (Souza-Lobo 1991), esta adquire diversas formas conjunturais e históricas. As diferenças observadas são produzidas historicamente e propagadas através de sistemas de representação, gramáticas de conduta no feminino e no masculino, fruto do processo de educação - que transcende o aparato escolar - e da socialização dos indivíduos (Saffioti 1995). Assim, qualidades e habilidades consideradas naturais à mulher como a docilidade, a menor combatividade, a maior sensibilidade aos problemas da família ou o desempenho de algumas atividades como a costura, são produto de educação e de formação, nem sempre adquiridas por vias formais e sim, por exemplo, como parte das atribuições de uma dona-de-casa.

A distribuição social de tarefas por sexo segue uma classificação hierárquica, expressão histórica de determinadas relações sociais de classe e gênero (Kergoat 1989). O gênero é entendido como um con- 
junto de representações sociais em torno do masculino e do feminino, construídas a partir das condições biológicas das diferenças entre os sexos; é "uma relação social cujo conteúdo varia enormemente, sem se deixar conhecer previamente, não obstante a existência de relações hegemônicas de gênero" (Saffioti 1995, p. 162).

Souza-Lobo (1991) destaca que é preciso ver as relações de trabaIho como interações que envolvem subjetividade, sendo o gênero uma das dimensões dessas subjetividades. Assim, a fábrica abriga processos de trabalho que produzem mercadorias, mas também produz e reproduz subjetividades. Nesse sentido, a divisão sexual do trabalho não pode ser considerada o locus fundamental das relações entre os sexos a partir do qual são determinadas as demais relações; tampouco as relações extrafabris esgotam a problemática das relações entre homens e mulheres no trabalho.

As relações de gênero são entendidas por estas autoras como parte das relações sociais e destas indissociáveis; sendo assim, não se trata unicamente de articular esferas casa/trabalho, trabalho doméstico/trabaIho remunerado ou atribuir condicionamentos de uma sobre outra, nem tampouco descrever diferenças, e sim problematizá-las identificando em cada prática o que há de resistência, subordinação ou cumplicidade.

De acordo com Saffioti:

Não se trata de retalhar a realidade social, situando em cada fatia um tipo de processo social ou relações sociais. Ao contrário, trata-se de estar sempre alerta para detectar a presença das diferenças/semelhanças de gênero nas relações de produção, assim como as diferenças/semelhanças de classe nas relações de gênero (...) esses dois tipos de relações são absolutamente recorrentes, impregnando todo o tecido social. (1992, p.192)

Abreu (1993a) aponta que, para se compreender as relações entre inovação tecnológica e divisão sexual do trabalho, por setor de atividade e por tarefas, a questão da qualificação é passagem obrigatória. A construção social das qualificações passa por um processo de distinção entre tipos de trabalho e de trabalhadores que os executam.

Segundo Castro (1992), a qualificação é uma dimensão importante na definição de coletivos, na construção de identidades e de interesses de grupos sociais específicos. Nessa medida, a qualificação deve ser entendi- 
da não somente como um conjunto de características das rotinas de trabaIho ou tipos de conhecimentos necessários para realizar uma dada função (qualificação de um posto de trabalho), expressos em termos de tempo de aprendizagem, de escolaridade. Deve-se considerar a margem de controle dos trabalhadores sobre o processo produtivo, bem como aspectos da personalidade. A qualificação nem sempre está fundada em características do tipo aquisitivo. Qualidades do tipo adscrito, marcas de identidade que acompanham os indivíduos, associadas à tradição e ao costume, constituem importantes componentes do perfil da qualificação dos trabalhadores.

De acordo com a referida autora,

estão em jogo não apenas estratégias gerenciais de controle do trabalho e de extração de mais-valia (ao modo mais clássico), mas também as estratégias dos trabalhadores, complexas, competitivas e multifacetadas. Trata-se de estratégias coletivas, conquanto não necessariamente classistas, que sustentam identidades fundadas na defesa de campos de interesse profissional, voltadas para a produção e reprodução das barreiras de acesso a mundos cujas definições são social e culturalmente construídas, mas politicamente praticadas.(Castro 1992, p. 218)

A divisão sexual do trabalho mostra onde estão os homens e as mulheres no mundo do trabalho, como no caso do trabalho feminino majoritário na indústria do vestuário e em tarefas específicas tais como as atividades de costura. No entanto, para não cair em explicações baseadas na natureza de homens e mulheres, o lugar atribuído a uns e outros só pode ser compreendido quando dimensionado em termos históricos e sociais. Um trabalho feminino não é um trabalho que só pode ser exercido por mulheres devido, necessariamente, a qualidades intrínsecas a estas e, sim, um trabalho que passou a ser exercido por mulheres e envolve representações e práticas sociais construídas e, muitas vezes, cristalizadas pela tradição. Para compreender a divisão sexual do trabalho é preciso ter em conta a questão da qualificação profissional como uma construção social e o mundo do trabalho como uma esfera onde a subjetividade e as identidades são produzidas, mas também reproduzidas de acordo com relações sociais de classe e gênero.

$\mathrm{Na}$ indústria do vestuário predominam a mão-de-obra feminina e, também, como se verá nos dados apresentados a seguir, os baixos sa- 
lários, a baixa escolaridade e a alta rotatividade. No entanto, no caso estudado, são identificadas algumas alterações deste perfil, surgindo novas oportunidades profissionais, particularmente para as trabalhadoras, a partir das mudanças que vêm ocorrendo na empresa.

\section{A indústria do vestuário}

As inovações técnicas nesse segmento da indústria não se desenvolveram de forma igual para a totalidade do processo produtivo, estando mais avançadas nas etapas anteriores à costura. O principal equipamento utilizado na costura, a mais intensiva em trabalho, é a máquina de costura, datada do século XIX e apresentando as mesmas características básicas até hoje. As diversas gerações de máquinas de costura (manivela, pedal, motor e programáveis), bem como os vários tipos de máquinas que realizam operações específicas (costura reta, curva, diferentes pontos e tarefas), apesar das facilidades, não alteram significativamente 0 tempo de produção (Scherer e Campos 1995). Lamphere indica que a maior parte do tempo é gasta no manuseio do material, passando as costureiras $20 \%$ de seu tempo efetivamente trabalhando (apud Abreu 1986).

A indústria do vestuário caracteriza-se, assim, de um modo geral, por processos relativamente pouco automatizados e permanece bastante dependente da mão-de-obra direta. Predominam baixos níveis salariais, baixa escolaridade e alta rotatividade. Segundo dados da Rais/MTb, no Rio Grande do Sul, em 1994, 45,23\% da mão-de-obra empregada ${ }^{1}$ ganhavam de 1 a 2 salários mínimos. De acordo com a mesma fonte, a faixa de maior concentração de empregados, quanto ao grau de instrução, correspondia, naquele ano, à $8^{\mathrm{a}}$ série incompleta, a qual abrangia $33,6 \%$ dos empregados. Entre os desligados da indústria do vestuário, 49,02\% haviam permanecido há menos de 1 ano no emprego, em 1996 (Caged/Módulo II/MTb). Quanto à distribuição dos empregados por faixa etária, em 1994, as faixas de maior concentração eram dos 30 aos 39 anos, correspondente a $28,47 \%$ dos empregados, e a dos 40 aos 49 anos, correspondendo a 22,15\% (Rais/MTb).

Ainda do ponto de vista do emprego, no Rio Grande do Sul, a indústria do vestuário apresenta baixa participação no conjunto do setor industrial do estado, representando, em 1994, 2,52\% do total da mão-deobra empregada na indústria de transformação. A presença feminina é, no 
entanto, majoritária: $80,45 \%$ da mão-de-obra empregada no ramo do vestuário é constituída por mulheres, representando $6,35 \%$ do total de mulheres empregadas na indústria de transformação do estado (Rais/MTb\1994).

A diversidade dos produtos fabricados pela indústria do vestuário, de acordo com o sexo, idade, mercado consumidor, tipo de tecido utilizado, e as diferentes finalidades de uma vestimenta, bem como a tecnologia barata, no caso das máquinas de costura, não impõem grandes barreiras para que novas empresas entrem no mercado. Segundo Abreu (1986), neste segmento da indústria, de um modo geral, as grandes empresas dedicam-se a produtos mais padronizados, que requerem modificações secundárias diante de mudanças da moda e de estações do ano, enquanto que as pequenas empresas voltam-se para produtos com vida comercial mais reduzida, mais influenciadas pelas variações da moda e pela sazonalidade dos produtos.

O ramo do vestuário no Rio Grande do Sul compõe-se de um grande número de micro e pequenas empresas e um número reduzido de empresas de porte médio ou grande. Dados da Rais (estabelecimentos/MTb para 1994), revelam que, do total de estabelecimentos do ramo no estado, $92,73 \%$ são microempresas (até 19 empregados), $6,03 \%$ são pequenas (de 20 a 99 empregados), 1,11\% são médias (de 100 a 499 empregados) e $0,14 \%$ são grandes empresas (mais de 500 empregados). Do ponto de vista da distribuição dos empregados no ramo, de acordo com o tamanho dos estabelecimentos, 35,96\% empregam-se em microempresas; $25,93 \%$ em pequenas; e $25,73 \%$ e $12,39 \%$ dos empregados, em médias e grandes empresas, respectivamente (Rais estabelecimentos/MTb 1994).

Segundo informações obtidas no Sindicato da Indústria do Vestuário do Rio Grande do Sul, a maior parte dessas micro e pequenas empresas são produtoras de moda feminina, onde predomina o trabalho autônomo com vendas direto ao consumidor. Convém destacar, ainda, a existência de parcela considerável de empresas não registradas, "de fundo de quintal", e o papel das conhecidas "sacoleiras" na venda desses produtos.

Scherer e Campos (1995) alertam que o poder de uma empresa nem sempre está refletido no número de empregados diretos sob seu controle. Freqüentemente, empresas de dimensões variadas atuam como subcontratadas de outras empresas. A subcontratação ocorre como uma alternativa para flexibilizar a produção, reduzir custos e responder a picos de demanda. 
A descontinuidade entre as cinco etapas compreendidas no processo produtivo - criação dos modelos, modelagem (confecção, ampliação e encaixe dos moldes), corte dos tecidos, montagem (ou costura, por sua vez divisível em uma multiplicidade de pequenas tarefas) e acabamento - favorece a subcontratação. Em alguns casos, a empresa pode ser um "laboratório de moda", responsável pela criação, pela modelagem e pelo corte, etapas consideradas mais importantes para a qualidade do produto final e que requerem maiores qualificações dos trabalhadores (Spindel 1983). As chamadas facções de costura são empresas subcontratadas, especialistas em uma ou mais etapas do processo produtivo, geralmente a etapa mais intensiva em trabalho, a costura.

O ramo do vestuário, no Rio Grande do Sul, correspondia, em 1993, a $1,33 \%$ do valor adicionado fiscal em relação ao total do valor adicionado da indústria no Rio Grande do Sul (Secretaria da Fazenda/RS). Contudo, esta realidade nem sempre foi a mesma: dos anos 50 até os 70 a indústria do vestuário equivalia a $10 \%$ da arrecadação de impostos provenientes do setor industrial no estado, contando com um número considerável de grandes empresas com mais de mil empregados. No contexto de recessão econômica dos anos 80 , muitas das grandes empresas, geralmente empresas familiares, faliram, dividiram-se ou extinguiram-se devido a problemas gerenciais e de mercado. (informações obtidas junto ao Sindicato das Indústrias do Vestuário do Rio Grande do Sul).

Este quadro foi ainda mais reforçado pela abertura econômica e a reordenação dos mercados em nível mundial, impondo novos padrões de concorrência tanto no mercado interno, com a entrada dos produtos importados, quanto no mercado externo, para as empresas exportadoras.

Das grandes empresas do Rio Grande do Sul, poucas ainda permanecem. Entre estas encontra-se a empresa investigada, localizada em Porto Alegre e fundada nas primeiras décadas do presente século. A antiga empresa familiar sobreviveu às constantes crises de mercado pela venda, em 1973, de parte das ações a um grande grupo têxtil do país, pela redução do quadro funcional e, mais recentemente, pela busca de modernização.

A empresa investigada

A empresa possui 765 trabalhadores, dos quais 613 situam-se na área industrial. Sua produção é de 1.000 trajes por dia (paletós, calças 
masculinas e, eventualmente, coletes e trajes femininos), atendendo o mercado nacional (Minas Gerais, Brasília e região sul/sudeste) e o mercado externo ( $30 \%$ da produção é destinada ao Chile, à Argentina e aos EUA). A empresa não terceiriza atividades ligadas à produção, mas, sim, serviços como alimentação, limpeza e vigilância.

O processo produtivo inicia-se propriamente pelo setor de modelagem, onde são criados os modelos, feitas as ampliações dos moldes, o encaixe e o risco dos diversos componentes dos modelos. O encaixe consiste em buscar a forma ótima em termos de aproveitamento dos tecidos que serão riscados e, posteriormente, passam para o setor de corte. Depois de cortadas, as peças são separadas e emitidas para a montagem, onde são costuradas. O setor de montagem na empresa investigada subdivide-se em três seções: de calça, de paletó e de acabamento; nesta última são realizadas as operações finais: os produtos já prontos são passados, revisados e embalados.

Os homens concentram-se nos setores de corte, manutenção, almoxarifado e em parte do setor de modelagem, e as mulheres, majoritárias na empresa, nas atividades de costura e de modelagem.

Nesta empresa, de grande porte, fabricante de roupa masculina, sem muitas variações em relação à moda ou à sazonalidade dos produtos, com grande dependência da mão-de-obra direta, a direção preocupa-se, acima de tudo, em padronizar e melhorar a qualidade de seus produtos Esta preocupação, aliada às formas de racionalizar custos, elevar a produtividade e, principalmente, sobreviver à crise econômica tornando a empresa competitiva no mercado, repercute em aquisição de equipamentos, implantação de programa de qualidade, esboços de gestão participativa, mudanças nas formas de produzir seu principal produto o paletó - e treinamento de pessoal.

As novas tecnologias

No que diz respeito à adoção de automação microeletrônica na empresa estudada, foram introduzidos máquinas eletrônicas, no setor de montagem, e sistema informatizado, no setor de modelagem.

No setor de montagem da empresa coexistem diversos níveis de atualização tecnológica dos equipamentos, como máquinas de costura mecâ- 
nicas e eletrônicas operando conjuntamente. Os investimentos com tecnologia nesse setor, a partir de 1992, vêm ocorrendo segundo a regularidade e a padronização que proporcionam ao produto. No caso de um paletó, por exemplo, a vista, o bolso pequeno e os demais bolsos devem estar padronizados, bem passados e, além disso, com um bom botão e um bom tecido. Foram adquiridas 4 máquinas eletrônicas para fazer a vista do casaco (a máquina distribui uma brandura eletronicamente e costura), 15 máquinas eletrônicas de costura comum (cortam o fio e posicionam a agulha); 1 máquina de cavar bolso (coloca-se a peça na máquina na posição correta e liga-se - a peça já está marcada para orientar a operadora); máquina de pregar manga e máquina de fazer a abertura da manga foram adquiridas recentemente.

No setor de modelagem, a informatização com a compra de equipamento CAD, em 1993, permitiu adaptar a produção à diminuição do tamanho dos lotes, agilizando o processo e reduzindo as perdas de matéria-prima. Desde então, a partir da introdução de uma peça padrão em uma mesa digitalizadora, a ampliação, o detalhamento, o encaixe dos moldes e o risco automático são feitos com o auxílio do computador. $O$ enfesto e o corte ainda não foram automatizados.

O tempo despendido da modelagem ao corte, no modelo tradicional, varia entre $10 \%$ e $15 \%$ do tempo total da produção (Dubois apud Scherer e Campos, 1995), enquanto que com a utilização do CAD há uma aceleração nas operações de pelo menos $50 \%$. Outro fator importante que reduz os custos diz respeito às sobras de tecidos: o encaixe automático permite uma redução aproximada de $4 \%$ na subutilização dos tecidos (Scherer e Campos op.cit.).

\section{O programa de qualidade total}

O programa de qualidade da empresa encontra-se em implantação desde 1994 por solicitação dos acionistas. O primeiro passo foi a formação de um comitê e a organização do programa "5S" - organização, limpeza, saúde, higiene e segurança. O comitê é composto por sete pessoas: diretor industrial, diretor superintendente, responsável pela qualidade na empresa, um representante da produção, dois representantes do setor de $\mathrm{RH}$ e um representante do setor administrativo. Os cursos iniciais de " $5 \mathrm{~S}$ " foram oferecidos para o comitê, posteriormente todos os supervisores realizaram os cursos e só então foi oferecido para todos os funcionários. 
Os funcionários foram divididos em grupos e treinados para o " $5 \mathrm{~S}$ " com vistas a saber o que é o programa de qualidade e como funciona, em reuniões de duas horas durante o expediente. Percebem-se alguns resultados em termos de limpeza, higiene e organização na fábrica: encontramse plantas ornamentando o ambiente, foram confeccionadas capas em forma de vestido para as máquinas de costura e as paredes da fábrica foram pintadas.

Para acompanhar o andamento da implantação do programa são realizadas auditorias permanentes pelo pessoal do setor de $\mathrm{RH}$ e pela responsável pela qualidade. Foi implantado ainda o Programa de Idéia e Melhoria que visa estimular a participação dos funcionários, sugerindo possíveis mudanças nas condições de trabalho ou no desempenho de operações.

\section{A organização da produção}

A produção na empresa organiza-se em linha e embora haja algumas tentativas de formar grupos que façam parte da produção integral de um produto, o trabalho é fundamentalmente baseado no parcelamento das tarefas. Não houve, na empresa, modificações recentes nas estruturas hierárquicas - direção, gerência, encarregado e supervisor.

Houve, no entanto, uma mudança no sistema de confeccionar o paletó, a partir da introdução do sistema de duas conchas, em 1992. Consiste na preparação do forro e da parte externa separadamente, seguidos da união das duas partes. Antes desta mudança na forma de produzir o casaco, ele era unido a cada operação (por exemplo, fazia-se a frente e juntava-se com o forro, fazia-se a manga e juntava-se e assim por diante). No sistema antigo, 230 funcionárias faziam 700 casacos por dia com mais de 200 operações, em 1996, 255 funcionárias no setor de casacos que fazem 1100 casacos com 110 operações. O tempo de produção do casaco também diminuiu: em 1994 um casaco era produzido em 324 minutos e, em 1996, passou para 186 minutos. Até 1996, a empresa obteve um ganho de produtividade de $76 \%$ na produção do paletó devido, em grande medida, aos ganhos provenientes da incorporação de equipamentos no setor de montagem e da modificação da forma de produzir o casaco..

$\mathrm{Na}$ empresa foi realizada ainda, no que concerne a organização da produção e do trabalho, uma reavaliação completa de tempos e movimen- 
tos, cronometragens e melhorias do método de execução das operações no setor de montagem. Esta reavaliação estendeu-se de outubro de 1995 a janeiro de 1996. Todas as funcionárias do setor de montagem foram reunidas em grupos e o grupo contratado para fornecer o treinamento conversou com todos sobre a necessidade da mudança e colaboração, com vistas a modificar hábitos operatórios. No entanto, era esperada uma economia nos custos do produto em trono de $10 \%$ e foi atingida apenas uma economia de $6 \%$.

Formas de ocupação, controle e qualificação

da mão-de-obra feminina

No setor de montagem da empresa são três os níveis hierárquicos: encarregadas (do casaco, do corte e da calça e do acabamento), supervisoras e costureiras.

As costureiras do setor de montagem são na sua grande maioria especialistas em uma ou mais operações. Uma trabalhadora do setor de manga de casaco, por exemplo, pode ser especialista somente em fazer a costura da manga. As atividades de costura, no entanto subdividemse em até cinco níveis com remuneração crescente. Cada nível caracteriza-se pelo domínio de determinadas operações. O requisito para atingir o nível 5 é ser uma costureira volante, saber/fazer oito operações.

A aprendizagem de costura para costureiras novas, bem como a mudança de nível de costura, ocorre pela observação e pelas instruções fornecidas pela encarregada do setor no próprio local de trabalho. A promoção, neste caso, acontece de acordo com as oportunidades (quando uma costureira falta, coloca-se outra que já tenha demonstrado interesse em realizar aquela operação). Os aumentos são gradativos, chegando ao máximo quando a costureira alcança a quantidade de produção exigida para cada tipo de operação.

Por exemplo, quando há uma oportunidade para fazer o ziguezague da gola, que é um trabalho muito delicado, pois é necessário saber onde colocar a brandura da vista, e é preciso muita atenção, a meIhor costureira 3 passa a realizar essas operações (de costureira 4) e, assim que atingir a produção correspondente àquela nova operação, passa a receber o salário de costureira 4. As supervisoras da empresa são selecionadas entre as costureiras de nível 5. 
Para operar os novos equipamentos, as instruções são fornecidas pelos técnicos (da empresa que vendeu os equipamentos) que vêm instalar as máquinas. As instruções são passadas primeiro para a encarregada do setor que, ao aprender a operar, ensina às funcionárias. As máquinas têm diversos programas por contagem de pontos, que são selecionados pelas operadoras; porém, quando se necessita alterar o número de pontos, os técnicos da manutenção é que fazem os ajustes. A máquina de cavar bolso, por exemplo, é programada para três tipo de bolso (cigarro, caneta e bolso normal). A máquina faz o primeiro, o segundo e o terceiro tipo de bolso sem mexer no programa. Todavia, se precisar aumentar o tamanho dos bolsos para um número de pontos que não está programado, então é preciso chamar os técnicos da manutenção (empregados da empresa).

As encarregadas do setor de montagem possuem uma grande experiência profissional na área de costura, em torno de 30 anos. São mulheres que tem em torno de 50 anos de idade e possuem escolaridade de $1^{\circ} \mathrm{grau}$ incompleto. Esse conhecimento muitas vezes lhes assegura participação nas decisões no que concerne a qualquer mudança efetuada na sua área de trabalho (no caso o setor do qual é encarregada: setor de calça, casaco ou acabamento).

São elas as trabalhadoras da empresa (juntamente com a piloteira do setor de modelagem) mais qualificadas na atividade de costura: sabem fazer todas as operações necessárias para produzir peças inteiras (um casaco, uma calça). Esta qualificação foi obtida por treinamento informal e aprimorada ao longo de suas trajetórias profissionais dentro da empresa.

As atividades de uma encarregada consistem na administração das respectivas seções (casaco, corte e calça): são responsáveis pela produção (atingir a produção detectando os erros e deslocando as costureiras de forma a administrar as ausências), pela qualidade dos produtos e pelo parecer final para a admissão de novas funcionárias. São responsáveis ainda por todo o treinamento para as costureiras novas e para as antigas, quando é preciso realizar novas operações.

Convém salientar que o treinamento institucional fornecido pelo SENAI dirige-se para trabalhadores autônomos, micro e pequenos empresários, bem como para a assistência técnica. Não há programas para formação de mão-de-obra especializada em costura industrial para a grande indústria.

$\mathrm{Na}$ empresa investigada, inexistem critérios definidos para a admissão de funcionárias no que se refere a possuir ou não experiência 
em costura. Segundo o diretor industrial, o importante é que a funcionária queira colaborar e tenha vontade de aprender. Nesta medida, o programa de qualidade em implantação na empresa tem como eixo principal melhorar a qualidade das operações de costura e melhorar as condições do ambiente físico da fábrica, investindo em educação e em sensibilização das trabalhadoras para os problemas enfrentados pela empresa no mercado. São oferecidos cursos rápidos para todos os trabalhadores da empresa em que são apresentados os objetivos do programa de qualidade e a necessidade de colaboração.

As novas qualificações que tendem a ser requeridas pela empresa da maior parte das trabalhadoras são comportamentais, tais como: interesse pelo trabalho, responsabilidade, envolvimento e comprometimento. No que concerne às trabalhadoras do setor de costura, o objetivo da empresa é buscar sua colaboração para a melhoria da qualidade dos produtos e também para a execução de operações de acordo com o tempo ótimo definido. O Programa de Idéia e MeIhoria é outra forma de buscar a participação das funcionárias, sugerindo possíveis mudanças nas operações ou nos itens do programa de qualidade ligados à limpeza e organização.

Às encarregadas e supervisoras, todavia, são oferecidos diversos cursos de relacionamento, com o objetivo principal de humanizar as relações entre trabalhadoras e chefias. O modelo de chefes intermediários demandados pela empresa é de profissionais extremamente hábeis no trato com as pessoas.

Estas mudanças de comportamento já tornam-se quantificáveis na empresa. Segundo a direção, a rotatividade, que em 1994 chegou a quase $90 \%$ na produção, cujas causas residiam fundamentalmente nas relações autoritárias entre trabalhadoras e chefias, reduziu-se para 3,3\% em abril de 1996.

Apesar de a organização do trabalho no setor de montagem estar baseada no parcelamento de tarefas e na reafirmação de práticas tayloristas, como o estudo de tempos e movimentos de execução das operações de costura. a tendência geral na empresa é exigir das costureiras a realização de várias operações. Isto ocorre principalmente tendo em vista o absenteísmo, um dos problemas enfrentados pelas encarregadas de setor, que todo o dia têm que administrar as faltas das trabalhadoras alocando funcionárias de uma a outra máquina, abrindo, assim, oportunidades para as costureiras efetuarem novas operações. 
A necessidade da empresa é, assim, de que as costureiras façam diversas operações, não somente em função das faltas mas também devido à diminuição do tempo de produção. Isso se deve tanto à introdução de novos equipamentos, como máquinas para abrir bolsos e máquinas com contagem de pontos programáveis que posicionam a agulha e cortam o fio automaticamente, quanto pela introdução do sistema duas conchas e pela padronização das operações a partir da reavaliação dos tempos e movimentos. Por exemplo, para produzir 1000 peças por dia, se antes eram necessárias duas pessoas, 500 peças para cada uma, com as mudanças, uma funcionária passou a fazer 700 peças e a outra 300; para esta segunda sobrou tempo para fazer outras operações.

A generalização deste processo esbarra, contudo, na resistência das trabalhadoras que não aceitam fazer mais operações. Com a máquina de fazer a vista do casaco (que distribui a brandura da vista eletronicamente) ainda não se conseguiu atingir a produção de mil peças por dia; cada operadora teria que fazer 250 . Segundo a encarregada do setor de casacos da empresa, elas acham que antes faziam 100 e era só alinhavado (a brandura) e agora tem que fazer 250 da operação completa. Ou ainda, durante o treinamento, as pessoas dizem que vão controlar os movimentos e cuidar da qualidade da operação; não o fazem.

A escolaridade está longe de ser um critério de recrutamento para as atividades de costura na empresa. A escolaridade média da mão-deobra empregada é muito baixa. Existem muitos analfabetos e as chefias intermediárias possuem, no máximo, $1^{\circ}$ grau incompleto. A perspectiva do diretor industrial é de que para atingir os objetivos da empresa e elevar a qualidade dos produtos não é necessário alterar este quadro: a funcionária não precisa aprender a ler para saber se uma costura está bem ou mal feita,

Mesmo assim, a empresa mantém um curso supletivo desde 1991 de $1^{\text {a }}$ a $4^{\text {a }}$ série do $1^{\circ}$ grau e, a partir de 1996, foi implementado o telecurso 2000 para completar as demais séries do $1^{\circ} \mathrm{grau}$. As aulas são realizadas após o expediente, com duração de duas horas durante um ano e meio. Desde que começou o programa de escolarização, foram formadas em torno de 100 pessoas, até a 4 série.

Os cursos supletivos são voluntários e oferecidos preferencialmente aos encarregados, supervisores e aos funcionários mais antigos da empresa. Se para o exercício das atividades de costura a escolaridade não é um entrave, a baixa escolaridade das chefias intermediárias aca- 
ba constituindo-se em um problema para a empresa, tendo em vista, por exemplo, as dificuldades por elas enfrentadas para dirigir reuniões simples de auditoria dentro do programa " $5 S$ " (verificar se só há materiais necessários no setor e se estes materiais estão identificados). Além disso, na realização dos cursos para a reavaliação dos tempos e movimentos, envolvendo noções de matemática, dos quais deveriam participar supervisoras e encarregadas, muitas delas não conseguiram acompanhar, tendo em vista não dominarem estes conhecimentos básicos.

Mesmo não sendo um critério seletivo da mão-de-obra, aumentar a escolaridade torna-se uma forma eficaz de sensibilização das funcionárias da costura. A funcionária toma consciência da situação de sua empresa no mercado e a empresa pode medir seu interesse no que concerne às suas principais exigências, ou seja, funcionárias comprometidas e aptas a cooperar dando sugestões quanto a possíveis mudanças nas condições de trabalho ou no desempenho de operações. Funcionárias que querem aprender e estudar são as funcionárias que querem se envolver e, até certo ponto, permanecer na empresa.

Se no setor de montagem as mudanças requeridas pela direção da empresa em relação às qualificações são comportamentais, muito embora sejam indissociáveis do saber/fazer, pois têm como finalidade repercutir na melhoria da qualidade dos produtos, no setor de modelagem, em estreita correlação com a introdução de tecnologia automatizada, são oferecidos cursos técnicos às trabalhadoras. Ainda que estas demandas estejam direcionadas para segmentos restritos da força de trabalho empregada na empresa como um todo, constituem oportunidades de reinserção, treinamento e melhor remuneração para algumas mulheres.

A partir da introdução do sistema CAD, no setor de modelagem, em 1993, além da adaptação da produção à diminuição do tamanho dos lotes, agilizando-a e otimizando o aproveitamento dos tecidos, houve redução e integração de operações das etapas anteriores à montagem É o caso de atividades como ampliação dos moldes, encaixe e risco.

O modelo é, desde então, criado com o auxílio do computador, já que se podem reutilizar os dados anteriormente inseridos no sistema; ou, depois de feito o modelo-base em papel, este é introduzido no sistema através de uma mesa digitalizadora. A ampliação de cada um dos componentes, necessários para que a vestimenta seja fabricada em suas diferentes numerações, passa a ser automática a partir de regras anteriormente introduzidas nos programas operacionais do sistema CAD. No momento em que há da- 
dos sobre o tamanho dos componentes de um modelo (manga, frente, costas, forro colante...) e dados sobre o tamanho e o tipo de tecido que será cortado (xadrez, liso...), o encaixe das peças é simulado em uma tela de computador, para depois ser mandada a ordem de risco automático.

Antes da introdução desse sistema, quatro trabalhadoras faziam a ampliação e oito encaixavam; atualmente, a ampliação é realizada pela supervisora do setor, e o encaixe, por três trabalhadores, duas mulheres e um homem.

O posto de trabalho de supervisora do setor de modelagem foi aberto com a introdução do sistema CAD. Esta é responsável por todo o suporte técnico: ajuda a resolver as dúvidas que o modelista tem no que concerne ao sistema, faz os controles de risco, controla o consumo, o estoque e a entrada de tecido, programa as ampliações e a entrada do modelo no sistema. Com 21 anos de idade, possui formação técnica pelo CETIQT, Centro Tecnológico da Indústria Química e Têxtil, no Rio de Janeiro, cuja duração é de 3 anos e meio, com especialização em malharia e confecção. Terminado o curso foi chamada para estagiar durante seis meses na empresa, quando trabalhou em diversas seções da fábrica. Nos dois últimos meses do estágio foi para a modelagem trabalhar com o sistema (na época, 1993, em implantação), quando foi efetivada. Conhece, portanto, todas as etapas do processo produtivo, desde a confecção de roupas até a programação e operação do sistema CAD utilizado pela empresa.

As duas mulheres analistas de encaixe eram antigas riscadeiras que, depois de 19 e 20 anos trabalhando com lápis ou giz, régua e papel em torno de uma mesa, passaram a operar um computador, "puxando" os modelos já inseridos no sistema e fazendo o encaixe das peças. Antes das mudanças, estas duas funcionárias tinham que estender o papel (para riscar os moldes a serem cortados), medir a largura, encaixar os modelos, riscar, enrolar o papel e passar os riscos para a enfestadeira do tecido. Ao mudar o conteúdo do trabalho, a partir das inovações tecnológicas, tornou-se mais fácil detectar os erros. Receberam um aumento salarial de $100 \%$, além de terem as suas condições de trabalho melhoradas (a sala da modelagem é um ambiente mais limpo, com ar condicionado). Ambas têm mais de 40 anos de idade e estão fazendo o curso supletivo, com aulas na empresa, para terminar $01^{\circ} \mathrm{grau}$.

As analistas de encaixe foram treinadas durante uma semana por uma instrutora proveniente de São Paulo, enviada pela empresa de onde foi comprado o equipamento CAD, quando de sua instalação. Após o 
período de aprendizagem, as atualizações do sistema passaram a ser recebidas periodicamente através de livros e manuais, onde constam as modificações e os aprimoramentos do sistema. A supervisora é responsável por repassar às funcionárias essas informações.

O setor de modelagem é o setor com mais baixa rotatividade na empresa, onde a maioria dos trabalhadores tem no mínimo nove anos de atividade na função, à exceção da supervisora do setor, cuja função, conforme aludido anteriormente, foi aberta a partir da introdução do sistema CAD, em 1993.

\section{Considerações finais}

As metas da direção da empresa investigada, cuja revisão de estratégias decorre principalmente do acirramento da concorrência no mercado interno e externo, dirigem-se fundamentalmente para a busca da padronização e da melhoria da qualidade dos produtos, para a eliminação dos estoques e a agilização da produção. Estas metas, aliadas à racionalização de custos e ao aumento da produtividade, direcionam as estratégias adotadas para a combinação de métodos tayloristas com novas práticas de gestão da produção, incorporação de equipamentos em pontos estratégicos da produção, bem como treinamento de pessoal.

Essas transformações que vêm ocorrendo no caso estudado, tendo em vista as características do ramo do vestuário no Rio Grande do Sul, não afetam essencialmente o modelo tradicional de uso da mão-de-obra, no caso, feminina.

A organização do trabalho no setor de montagem permanece baseada no parcelamento de tarefas e na reafirmação de práticas tayloristas como o estudo de tempos e movimentos de execução das operações de costura. Ainda que haja a necessidade da realização de várias operações, principalmente para cobrir as ausências das funcionárias, o andamento desse processo esbarra com as resistências das trabalhadoras, pois apenas teriam que aumentar o ritmo de trabalho sem qualquer contrapartida salarial, nem mesmo incentivos à produtividade, inexistentes na empresa.

Os esforços empreendidos em relação à mudança nas práticas de gestão da força de trabalho direcionados para a mudança de atitude em relação ao trabalho, no que concerne tanto à melhoria do ambiente físi- 
co, quanto à humanização das relações entre trabalhadores e chefias, demandam posturas mais participativas por parte das trabalhadoras.

As novas qualificações que tendem a ser requeridas, neste contexto, à maior parte das trabalhadoras, são comportamentais, como: interesse pelo trabalho, responsabilidade, envolvimento e comprometimento. Para as costureiras estas mudanças comportamentais visam à sua sensibilização para a cooperação na melhoria da qualidade dos produtos e o treinamento é realizado através de cursos rápidos em que são apresentados os objetivos do programa de qualidade e a importância da participação das funcionárias para a sobrevivência da empresa em um mercado altamente competitivo. Já o treinamento das encarregadas e supervisoras do setor de montagem direciona-se para cursos de relacionamento, mas salienta-se a importância de sua experiência profissional na área de costura.

Assim, apesar dos programas de elevação da escolaridade e das tentativas de diminuir a rotatividade, o treinamento no setor de montagem dirige-se para mudanças comportamentais. Percebe-se que para melhorar a qualidade das operações de costura, tendo em vista o produto final, a empresa não se preocupa em investir no treinamento técnico das trabalhadoras, comprometê-las com a empresa é o objetivo. No setor de modelagem, todavia, em estreita correlação com a introdução de tecnologia automatizada, surgem demandas de elevação da qualificação técnica das trabalhadoras. Ainda que estas demandas estejam direcionadas para segmentos restritos da força de trabalho empregada na empresa como um todo, constituem oportunidades de reinserção, treinamento e melhor remuneração para algumas mulheres. É o caso das trabalhadoras do setor de modelagem, e do setor de corte, um setor considerado masculino dentro da indústria do vestuário, onde estão sendo treinadas mulheres para exercerem estas atividades.

Conforme salientado anteriormente, a divisão sexual por setores e tarefas não pode ser entendida em razão de habilidades naturais das mulheres no exercício das atividades de costura, por exemplo; é antes uma forma de apropriação pela grande indústria de um saber que por muitos séculos foi uma das atribuições da mulher na esfera doméstica. Em nossos dias, porém, trata-se de uma noção de saber feminino muito mais em decorrência das representações (e práticas) sociais acerca do feminino do que propriamente adquirido na esfera doméstica. Como aponta Abreu (1993b), operárias do setor de costura em grandes empresas são consideradas qualificadas por outros critérios, não implicando necessariamente no conhecimento global de produção de uma roupa e, sim, no uso de diferentes máquinas com igual proficiência e velocidade. 
Se outros estudos destacam que a tendência da grande indústria neste segmento é de que as mulheres permaneçam nas atividades de costura e não passem a integrar as atividades melhor remuneradas e consideradas mais qualificadas como as atividades do setor de corte e modelagem, cuja aprendizagem demanda treinamento técnico apurado, a empresa investigada contraria estas tendências. Aponta desta forma para a emergência de novas formas de uso da força de trabalho feminina, bem como para dimensões da qualificação como comportamento, características pessoais, tradição e costume.

Sendo assim, verifica-se que, por um lado, o trabalho feminino no caso estudado está baseado em movimentos rotineiros, homogêneos e automáticos, cuja qualificação vêm acompanhada de construções sociais em torno do feminino e demanda um comportamento determinado, o interesse, o envolvimento. No setor de costura, o treinamento técnico das costureiras restringe-se às instruções das encarregadas, no próprio local de trabalho, estas sim com larga experiência e conhecimentos em costura. Por outro lado, o contexto de transformações por que passa a empresa investigada, particularmente com a introdução de tecnologia microeletrônica no setor de modelagem e as pontuais, porém novas oportunidades de treinamento técnico daí advindas, faz com que surjam também novos trabalhos desempenhados por mulheres baseado em uma multiplicidade de tarefas.

Conforme aponta Abreu (1993a), os estudos sobre qualificação passam pela questão da divisão sexual do trabalho e é a categoria gênero que confere a dimensão histórico social essencial para o aprofundamento da questão. Assim, a divisão sexual do trabalho apresenta-se, no caso das atividades de costura, extremamente associada ao envolvimento simbólico ligado ao sexo de quem as executa e a tradição, mas também é preciso perceber que se modifica. A sociedade se modifica e surgem novas oportunidades e espaços para as mulheres e, mesmo que ainda restritos e longe do que se poderia esperar de um trabalho plenamente realizador, no caso estudado em uma grande empresa produtora de roupas, cujo trabalho está baseado no uso intensivo de mão-de-obra, isso não é diferente.

Nota:

1. Os dados coletados da RAIS/94 referem-se aos empregados em atividade em $31 / 12$ do referido ano na classe de atividade econômica CNAE-95 Confecção 
de outras peças do vestuário e os dados do CAGED referem-se à subatividade IBGE confecção de roupas agasalhos e peças, conforme a tabela de correspondência entre subatividade e classe de atividade do MTb.

\section{Women's work in the clothing industry: a case study}

ABSTRACT: This article analyzes the changes that have occured in a major company of the clothing field in the state of Rio Grande do Sul and its relations concerning the chores, control and qualification of female labour. Most female workers of this company hold a low schooling level, a low salary and their chores are organised in a taskbased pattern. However, since microeletronic technology and new forms of labour management have been applied in this company, new opportunities for training and professional reintegration have arisen in strategic production sectors for some women.

\section{Bibliografia}

ABREU, Alice Rangel de Paiva. O avesso da moda: Trabalho a domicílio na indústria de confecção. São Paulo, Hucitec, 1986.

. "Mudança tecnológica e gênero no Brasil: Primeiras reflexões". Novos Estudos Cebrap no 35. São Paulo, Cebrap, 1993a.

. "Trabalho e qualificação na indústria de confecção". Estudos Feministas, oㅡ 2. Rio de Janeiro, Ciec/ECO/UFRJ, 1993b, vol. 1.

BRUSCHINI, Cristina. "O trabalho da mulher no Brasil: Tendências recentes". Anais do III Encontro Nacional de Estudos do Trabalho. Rio de Janeiro - Abet, 1993, v. 1.

CASTRO, Nadya A. "Organização do trabalho, qualificação e controle na indústria moderna". In: Lucília R. de S. Machado et alii. Trabalho e Educação. Campinas, Papirus, 1992.

KERGOAT, Daniele. "Da divisão do trabalho entre os sexos". In: Helena Hirata (org.). Divisão capitalista do trabalho. Tempo Social no 1, São Paulo, USP, 1989, v. 2.

PENA, Maria Valéria Junho. Mulheres e trabalhadoras: presença feminina na constituição do sistema fabril. Rio de Janeiro, Paz e Terra, 1981. 
SAFFIOTI, Heleieth. "Rearticulando gênero e classe social". In: Albertina de O. Costa \& Cristina Bruschini (org.). Uma questão de gênero. Rio de Janeiro, Rosa dos Tempos; São Paulo, Fundação Carlos Chagas, 1992.

. "Diferença ou indiferença: Gênero, raça/etnia, classe social". In: Sérgio Adorno (org.). A sociologia entre a modernidade e a contemporaneidade. Cadernos de Sociologia no especial. Porto Alegre, PPG-Sociologia/UFRGS, 1995.

SCHERER, André e CAMPOS, Sílvia. Projeto Competitividade e Inovação na Indústria Gaúcha: Cadeia Produtiva Têxtil-Vestuário. Porto Alegre, FEE, 1995.

SOUZA-LOBO, Elisabeth (1991). A classe operária tem dois sexos: Trabalho, dominação e resistência. São Paulo, Brasiliense, 1991.

SPINDEL, Cheywa. "O 'uso' do trabalho da mulher na indústria do vestuário". In: Carmen Barroso \& Albertina de Oliveira Costa (orgs.) Mulher, mulheres. São Paulo, Fundação Carlos Chagas, 1983.

CAGED módulo II - Cadastro Geral de Empregados e Desempregados (1996). Ministério do Trabalho, Secretaria de Políticas de Emprego e Salário, 1996.

ESTATÍSTICAS ECONÔMICO-FISCAIS. Secretaria da Fazenda, Governo do Estado do Rio Grande do Sul, 1993.

RAIS - Relação Anual de Informações Sociais (1994). Ministério do Trabalho, Secretaria de Políticas de Emprego e Salário, 1994. 